\title{
Polycystic Ovary Syndrome (PCOS) Presenting with Delayed Menarche and Clitoromegaly
}

\author{
Sa'adatu T Sule* and Shedrach Anekwe \\ Department of Obstetrician/Gynaecology, Family Care Multi Clinics, Abuja, Nigeria
}

*Corresponding author: Sa'adatu T Sule, Department of Obstetrician/Gynaecology, Family Care Multi Clinics, 9, Lord Lugard Street, Asokoro, Abuja, Nigeria, Tel: 234-803-4000676

\begin{abstract}
Polycystic ovary syndrome can present with various features including delayed menarche, amenorrhoea, and enlarged clitoris, as was the case with the patient presented here. The diagnosis of PCOS can be challenging especially in young women and managing the condition may be complicated especially where metabolic effects such as type 2 diabetes occur as demonstrated in this case.
\end{abstract}

\section{Introduction}

Polycystic ovary syndrome (PCOS) can present with primary amenorrhoea by age 15 or more than 3 years after telarche [1] and may also present with features of hyperandrogenism such as hirsutism, acne, and elevated androgens [1-4]. Clitoromegaly can also result from hyperandrogenism although previous reports suggest that it is not a very common presentation of PCOS $[5,6]$ however, there is a suggestion that this may be because the external genitalia of PCOS patients are rarely examined [7]. PCOS is difficult to diagnose in adolescents $[2,3]$ especially those who are of normal weight in whom the condition tends to be diagnosed at an older age with ultrasound features of polycystic ovaries [2]. We present a case of a 22-year-old with normal weight who presented with delayed menarche followed by amenorrhoea, and signs of masculinisation including clitoromegaly.

\section{Case History}

A 22-year-old student presented in May 2018 with a history of amenorrhoea for one year. Her first menses was 2 years prior to presentation (at 20 years of age) and the bleeding was minimal and lasted only 1 day and the second episode of bleeding was one year after the first episode and she bled for one day. In both instances, the bleeding was scanty, bright red in colour and associated with mild lower abdominal pain but no other symptoms. In between these 2 episodes of bleeding, she did not have any symptoms. After the second episode of bleeding she started having intermittent non-radiating lower abdominal pain every 2 to 3 months. There were no aggravating or relieving factors and the last episode of lower abdominal pain was 1 month prior to presentation.

Her breasts started developing at the age of 14 years and she started wearing a bra at the age of 17 years. She did not have any breast pain and there was no history of nipple discharge. She started having pubic and axillary hair at the age of 14 years. She was para $0+0$ and had never had sexual intercourse. She had been having acne since she was 14 years of age. She had no history of chronic illness but was said to have been 'quite malnourished' as a child.

She is the first of 7 children of her mother, the next girl to her is her mother's $5^{\text {th }}$ child who was 12 -yearsold and yet to commence menses. Apart from her father who died of hypertension, there was no history of chronic illness in the family. She lived with her aunt and attended secondary school.

Physical examination revealed that her height was $1.48 \mathrm{~m}$ and she weighed $47.8 \mathrm{~kg}$ (body mass index 21.8 $\left.\mathrm{kg} / \mathrm{m}^{2}\right)$. She had moderate acne all over her face, chest and upper back. She did not have abnormal facial hair but had a lot of hair on her arms and legs, and a slightly

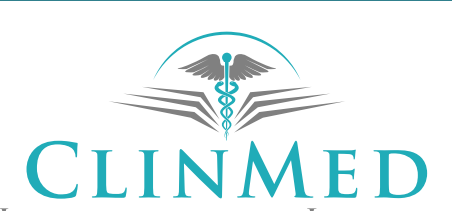

INTERNATIONAL LIBRARY
Citation: Sule ST, Anekwe S (2022) Polycystic Ovary Syndrome (PCOS) Presenting with Delayed Menarche and Clitoromegaly. Obstet Gynecol Cases Rev 8:218. doi.org/10.23937/2377-9004/1410218 Accepted: February 15, 2022: Published: February 17, 2022

Copyright: (C) 2022 Sule ST, et al. This is an open-access article distributed under the terms of the Creative Commons Attribution License, which permits unrestricted use, distribution, and reproduction in any medium, provided the original author and source are credited. 
husky voice. Her vital signs were normal. Her breasts were small but well developed and normal with no nipple discharge and no lumps. Her chest and abdomen were normal.

Pelvic examination revealed clean shaved pubic area with no extension of pubic hair to the abdomen, clitoral hood $3.5 \mathrm{~cm}$ long, clitoris about $3 \mathrm{~cm}$ long and $1 \mathrm{~cm}$ wide, prominent labia minora and small labia majora (Figure 1 and Figure 2). Her hymen was intact and the vagina opening appeared normal although the vaginal depth could not be ascertained digitally in view of the intact hymen.

The impression was delayed menarche, secondary amenorrhoea and masculinisation most likely due to hormonal imbalance.

Investigations revealed a karyotype of 46XX, serum testosterone of $4.05 \mathrm{ng} / \mathrm{ml}$ (normal $0.6-0.95 \mathrm{ng} / \mathrm{ml}$ ), steroid hormone binding globulin (SHBG) of 16.9 $\mathrm{nmol} / \mathrm{L}$ (normal 26.1-110.0 nmol/L), and antimullerian hormone of $130.3 \mathrm{ng} / \mathrm{ml}$ (excessive response $>2.56 \mathrm{ng} /$ $\mathrm{ml}$ ). Her full blood count, follicle stimulating hormone

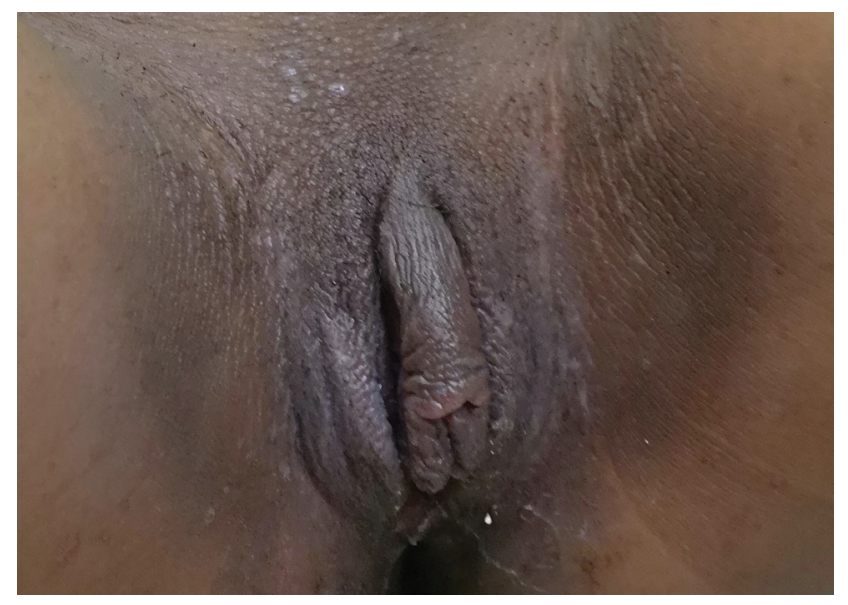

Figure 1: Enlarged clitoral hood.

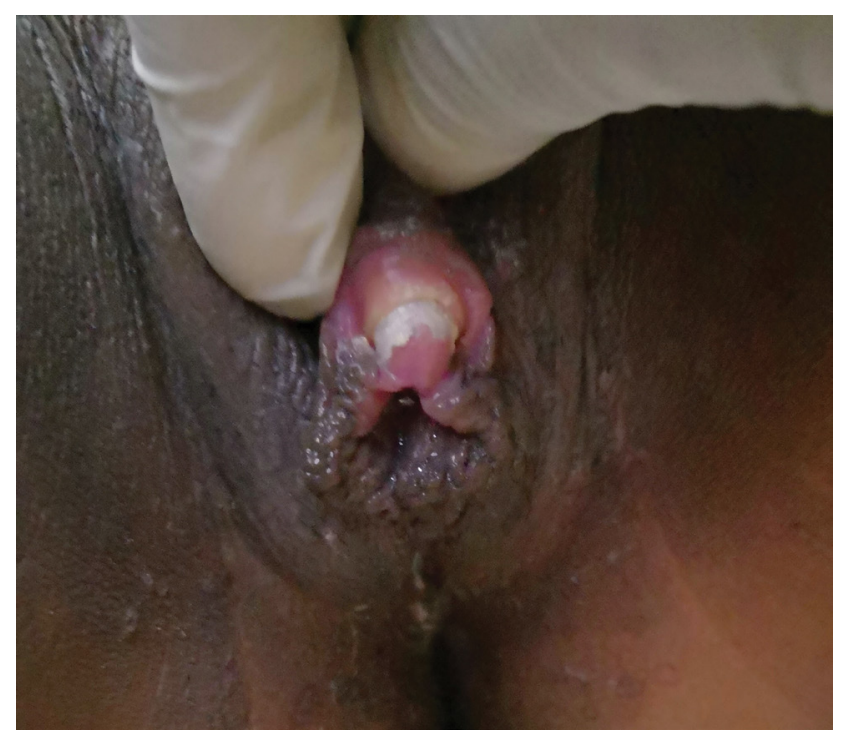

Figure 2: Enlarged clitoris.
(FSH), leutinising hormone (LH), prolactin, oestradiol, random blood sugar, thyroid function tests, lipid profile, and dehydroepiandosterone sulfate (DHEAS) were all within normal limits.

Both pelvic scan and pelvic MRI revealed a normal uterus and vagina, but both ovaries were enlarged and polycystic with multiple antral follicles of varying sizes that were widely distributed. The right ovary measured $4.7 \times 1.8 \mathrm{~cm}$, while the left ovary measured $5.2 \times 2.1 \mathrm{~cm}$. Her brain CT scan and abdominal ultrasound scan were both normal.

She was counselled on the diagnosis and commenced on cyproterone acetate $2 \mathrm{mg} /$ ethinyl estradiol $35 \mathrm{mcg}$ (Dianette) 1 tablet daily. She was also counselled on the danger signs to look out for while taking Dianette. Although she was informed about the option to have the clitoris surgically reduced, she declined this intervention.

She started menstruating one month after commencement of Dianette and menstrual periods lasted 4 to 5 days with moderate flow and no clots. Each episode of menstrual bleeding was associated with dysmenorrhoea on the second day only. Four months after commencement of Dianette, she was noted to have a fasting blood sugar (FBS) of $246 \mathrm{mg} / \mathrm{dl}$ (normal 70-110 $\mathrm{mg} / \mathrm{dl}$ ), a 2-hour postprandial blood sugar of $449 \mathrm{mg} / \mathrm{dl}$ (normal 0-199 $\mathrm{mg} / \mathrm{dl}$ ) and a glycosylated haemoglobin (HbA1C) level of $11.3 \%$ (normal $4.0-6.9 \%$ ). She was given dietary counselling, Dianette was discontinued, and she was commenced on metformin $500 \mathrm{mg}$ twice daily. At subsequent review 4 weeks later, she was having regular menses every month, and there was some improvement in her blood sugar profile (FBS 152 $\mathrm{mg} / \mathrm{dl}$ 2-hour postprandial $278 \mathrm{mg} / \mathrm{dl}$ and HbA1C 8.8\%). She was counselled on the need to follow the dietary advice and the dose of metformin was increased to 500 $\mathrm{mg}$ three times daily. Subsequently her blood sugar profile has normalised ranging between $89-101 \mathrm{mg} / \mathrm{dl}$ fasting blood sugar, $135-190 \mathrm{mg} / \mathrm{dl}$ 2-hour postprandial blood sugar, and 6.8-7.5\% glycosylated blood sugar. She is reviewed every 3 months and has been having regular menstrual periods and her vital signs, lipid profile, and hormonal profile have remained normal. She was last seen in December 2021 and had no complaints.

\section{Discussion}

The management of PCOS requires a high index of suspicion especially in adolescents and young people such as the case presented. Anti-androgenic agents such as cyproterone acetate in combination with ethinyl oestradiol are effective in treating PCOS [8] as was demonstrated in this case, however these agents may be associated with glucose intolerance [9] and care needs to be taken in PCOS patients who develop features of glucose intolerance or type 2 diabetes. On account of the deranged glucose profile, the treatment in this 
patient was changed to metformin which is the safe and preferred for young girls with PCOS who develop type 2 diabetes [10]. She continued to have regular menstrual cycles with metformin alone which is in keeping with previous reports showing that metformin treatment can result in regular menstruation and return of ovulation in PCOS patients $[1,10]$. This case highlights symptoms and signs with which PCOS can present in young women and the challenges of managing the condition.

\section{Declarations}

We declare that we do not have conflict of interest or external sources of funding in relation to this case report.

\section{References}

1. Pena AS, Witchel SF, Hoeger KM, Oberfield SE, Vogiatz MG, et al. (2020) Adolescent polycystic ovary syndrome according to the international evidence-based guideline. BMC Med 18: 72.

2. McManus SS, Levitsky LL, Misra M (2013) Polycystic ovary syndrome: Clinical presentation in normal-weight compared with overweight adolescents. Endocr Pract 19: 471-478.

3. Kosus A, Kamalak Z, Kosus N, Hizli D, Eser A (2016) Clitoral and labial sizes in women with polycystic ovary syndrome. J Obstet Gynaecol 36: 97-101.

4. Legro RS, Arslanian SA, Ehrmann DA, Hoeger KM, Murad $\mathrm{H}$, et al. (2013) Diagnosis and treatment of polycystic ovary syndrome: An endocrine society clinical practice guideline. J Clin Endocrinol Metab 98: 4565-4592.

5. Azziz R, Carmina E, Dewailly D, Diamanti-Kandarakis E, Escobar-Morreale HF, et al. (2009) The androgen excess and PCOS society criteria for the polycystic ovary syndrome: The complete task force report. Fertil Steril 91: 456-488.

6. Papadakis G, Kandaraki EA, Tseniklidi E, Papalou O, Diamanti-Kandarakis E (2018) Polycystic ovary syndrome and nc-cah: Distinct characteristics and common findings. A systematic review. Front Endocrinol 10: 388.

7. Iezzi ML, Lasorella S, Varriale G, Zagaroli L, Ambrosi M, et al. (2018) Clitoromegaly in childhood and adolescence: Behind one clinical sign, a clinical sea. Sex Dev 12: 163174.

8. Ruana X, Kubba A, Aguilar A, Muecka AO (2017) Use of cyproterone acetate/ethinylestradiol in polycystic ovary syndrome: Rationale and practical aspects. Eur J Contracept Reprod Health Care 22: 183-190.

9. Behboudi-Gandevani S, Abtah H, Saadat N, Tohidi M, Tehrani FR (2019) Effect of phlebotomy versus oral contraceptives containing cyproterone acetate on the clinical and biochemical parameters in women with polycystic ovary syndrome: A randomized controlled trial. J Ovarian Res 12: 78.

10. Lanzo E, Monge M, Trent M (2015) Diagnosis and management of polycystic ovary syndrome in adolescent girls. Pediatr Ann 44: e223-e230. 